\title{
PENERAPAN STRATEGI PEMASARAN MELALUI PENDEKATAN PENGEMBANGAN PRODUK GUNA MENINGKATKAN VOLUME PENJUALAN PADA CV. SILVI MN PARADILA PARENGAN LAMONGAN
}

\author{
Hery Suprapto \\ Prodi Manajemen, Fakultas Ekonomi, Universitas Islam Lamongan \\ Jl. Veteran No.53A Lamongan \\ Telp. ( 0322 ) 324706, Faks. ( 0322 ) 324706 \\ herysuprapto20@gmail.com
}

\begin{abstract}
Abstrak
Penelitian kualitatif ini bertujuan untuk mengetahui apakah strategi pemasaran melalui pendekatan pengembangan produk yang dilakukan oleh perusahaan telah sesuai dan berhasil meningkatkan volume penjualan. Penelitian ini dilakukan pada suatu usaha yang bergerak di bidang tenun yakni CV. Silvi MN Paradila. Data diolah menggunakan beberapa metode pengujian yang merupakan langkah-langkah dari uji analisis SWOT, diantaranya dengan menggunakan analisis IFAS (Internal Factors Analysis Summary), EFAS (External Factors Analysis Summary) dan Matriks SWOT. Hasil dari Analisis SWOT yang dilakukan terhadap CV. Silvi MN Paradila menunjukkan bahwa perusahaan berada pada posisi kuadran I, yakni kekuatan yang dimiliki mampu mengatasi kelemahan dimiliki, serta peluang yang dimiliki perusahaan lebih banyak daripada ancaman yang dimiliki.
\end{abstract}

Kata kunci: strategi pemasaran, pengembangan produk, volume penjualan

\section{PENDAHULUAN}

Pemasaran adalah proses mengidentifikasi, menciptakan dan mengkomunikasikan nilai, serta membangun dan memelihara hubungan yang kuat dan memuaskan dengan pelanggan dengan tujuan menangkap nilai dari pelanggan sebagai imbalannya untuk memaksimalkan keuntungan perusahaan. Dalam pemasaran terdapat salah satu strategi yang disebut marketing mix atau bauran pemasaran. Elemen bauran pemasaran menurut Rambat Lupiyoadi (2013) adalah produk, harga, tempat, promosi, orang, proses dan bukti atau lingkungan fisik.
Dalam bauran pemasaran produk bisa dikatakan merupakan elemen dasar dan penting. Dikatakan penting karena dengan produk perusahaan dapat menetapkan harga yang sesuai, mendistribusikan dan menentukan promosi yang tepat untuk pasar sasaran. Produk diciptakan dengan tujuan untuk memenuhi kebutuhan dan keinginan konsumen. Menurut Tjiptono (2012) produk adalah segala sesuatu yang ditawarkan produsen untuk diperhatikan, diminta, dibeli, dan dikonsumsi pasar sebagai pemenuhan kebutuhan atau keinginan pasar yang bersangkutan. 
CV. Silvi MN Paradila adalah suatu usaha yang bergerak di bidang industri tekstil khususnya kain tenun yang berada di Desa Parengan, Kecamatan Maduran, Kabupaten Lamongan. Disinilah pengembangan produk secara terusmenerus perlu dilakukan agar CV. Silvi MN Paradila dapat mengikuti perkembangan zaman, sehingga dapat memenuhi kebutuhan dan kepuasan konsumen melalui terciptanya inovasiinovasi baru yang sesuai dengan perkembangan zaman untuk memenuhi kepuasan konsumen sehingga konsumen tidak merasa monoton dan bosan dengan produk yang selama ini dibuat.

Ketika pengembangan produk terusmenerus dilakukan dan ssesuai dengan kebutuhan dan kepuasan konsumen, maka konsumen akan merasa kebutuhan dan kepuasannya terpenuhi, pada tahap ini konsumen akan melakukan pembelian atau konsumsi ulang dan tidak menutup kemungkinan akan bersedia menjadi pelanggan setia. Semakin banyak konsumen yang terpuaskan, akan semakin banyak pula produk yang terjual.

Ketika penjualan mengalami peningkatan, maka secara otomatis pendapatan yang diperoleh CV. Silvi MN Paradila juga meningkat. Dengan demikian kelangsungan hidup perusahaan juga terjamin.

\section{KAJIAN PUSTAKA}

\section{Strategi Pemasaran}

Menurut Oentoro (2012) strategi pemasaran adalah pengambilan keputusankeputusan tentang biaya pemasaran, bauran pemasaran, alokasi pemasaran dalam hubungan dengan keadaan lingkungan yang diharapkan dan kondisi persaingan. Sedangkan menurut Tjiptono dan Chandra (2012) strategi pemasaran merupakan rencana yang menjabarkan ekspektasi perusahaan akan dampak dari berbagai aktivitas atau program pemasaran terhadap permintaan produk atau lini produknya dipasar sasaran tertentu.

\section{Bauran Pemasaran}

Elemen bauran pemasaran menurut Lupiyoadi (2013) adalah sebagai berikut:

1) Produk (Product)

Yaitu keseluruhan konsep objek atau proses yang memberikan sejumlah nilai kepada konsumen. Perlu diperhatikan dalam produk adalah konsumen tidak hanya membeli fisik dari produk saja, tetapi membeli manfaat dan nilai dari produk tersebut yang disebut "the offer".

2) Harga (Price)

Yaitu sejumlah pengorbanan yang harus dibayar oleh pelanggan untuk 
memperoleh produk atau jasa. Dalam penetapan harga harus diperhatikan kedua belah pihak. Kedua belah pihak tersebut adalah perusahaan dan konsumen.

3) Tempat (Place)

Berhubungan dengan dimana perusahaan bermarkas dan melakukan operasi atau kegiatan. Tempat juga menjelaskan tentang bagaimana sistem penyampaian yang akan di terapkan.

4) Promosi (Promotions)

Yaitu kegiatan yang dilakukan oleh perusahaan untuk mengkomunikasikan manfaat produk dan sebagai alat untuk mempengaruhi konsumen dalam kegiatan pembelian atau penggunaan jasa sesuai dengan keinginan dan kebutuhannya.

5) Orang (People)

Merupakan orang-orang yang terlibat langsung dan saling mempengaruhi dalam proses pertukaran dari produk jasa. Dalam hubungannya dengan pemasaran jasa, maka people yang berfungsi sebagai service provider sangat mempengaruhi kualitas jasa yang ditawarkan.

6) Proses (Process)

Merupakan gabungan semua aktivitas, umumnya terdiri dari prosedur, jadwal pekerjaan, mekanisme, aktivitas dan hal-hal rutin, dimana jasa dihasilkan dan disampaikan kepada konsumen.

7) Bukti/Lingkungan Fisik (Physical Evidence/Environment)

Merupakan lingkungan fisik perusahaan tempat jasa diciptakan dan tempat penyedia jasa dan konsumen berinteraksi, ditambah unsur berwujud apapun yang digunakan untuk mengkomunnikasikan atau mendukung peranan jasa itu.

\section{Pengembangan Produk}

$$
\text { Menurut Oentoro }
$$

pengembangan produk adalah kegiatan produsen dituntut untuk dapat kreatif agar mampu menciptakan sesuatu yang baru untuk ditawarkan kepada konsumen, sedangkan menurut Kotler dan Amstrong (2014) pengembangan produk adalah pengembangan produk original, perbaikan produk, modifikasi produk, dan merek baru yang perusahaan kembangkan dalam departemen riset.

Dengan kata lain pengembangan produk merupakan usaha untuk meningkatkan penjualan dengan cara memperbaiki produk yang sudah ada atau membuat produk baru yang bertujuan untuk memenuhi kebutuhan dan kepuasan konsumen.

\section{Volume Penjualan}

Penjualan adalah sumber pendapatan yang diperlukan untuk menutup ongkos 
atau biaya dengan harapan mendapatkan laba, (Tjiptono 2012). Sedangkan menurut Daryono (2011) volume penjualan merupakan ukuran yang menunjukkan banyaknya atau besarnya barang atau jasa yang terjual. Dari dua definisi tersebut, dapat disimpulkan bahwa penjualan merupakan sumber pendapatan perusahaan dari banyaknya barang yang dijual baik secara tunai ataupun secara kredit dalam jangka waktu tertentu. Kegiatan penjualan mempunyai peran yang sangat penting karena bila target penjualan tercapai, maka tujuan perusahaan untuk memperoleh pendapatan yang di targetkan akan tercapai pula.

\section{Analisis SWOT}

Menurut Kotler (2013) dalam Nuary (2016) analisis SWOT adalah evaluasi terhadap keseluruhan kekuatan, kelemahan, peluang dan ancaman. Sedangkan menurut Sutojo dan Kleinsteuber (2012) dalam Nuary (2016), analisis SWOT adalah menentukan tujuan usaha yang realistis, sesuai dengan kondisi perusahan dan oleh karenanya diharapkan lebih mudah tercapai. Selanjutnya menurut Rangkuti (2014) dalam Nuary (2016) mengemukakan bahwa Analisis SWOT membandingkan antara faktor eksternal peluang (opportunities) dan ancaman (threats) dengan faktor internal kekuatan (strenghts) dan kelemahan (weaknesses).

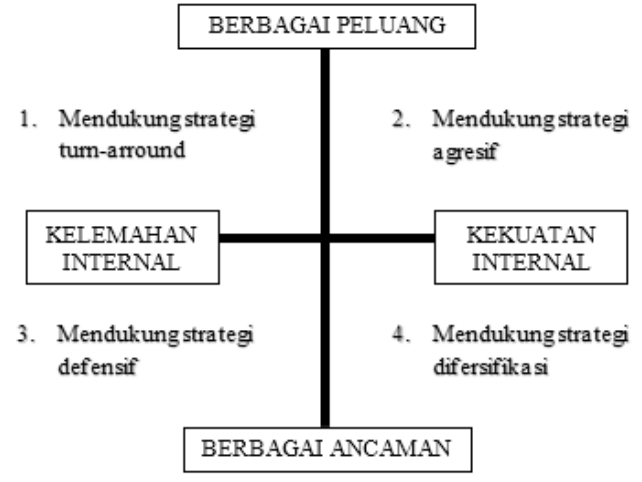

Gambar 1 diagram SWOT, Sumber (Rangkuti 2016)

\section{Kerangka berfikir}

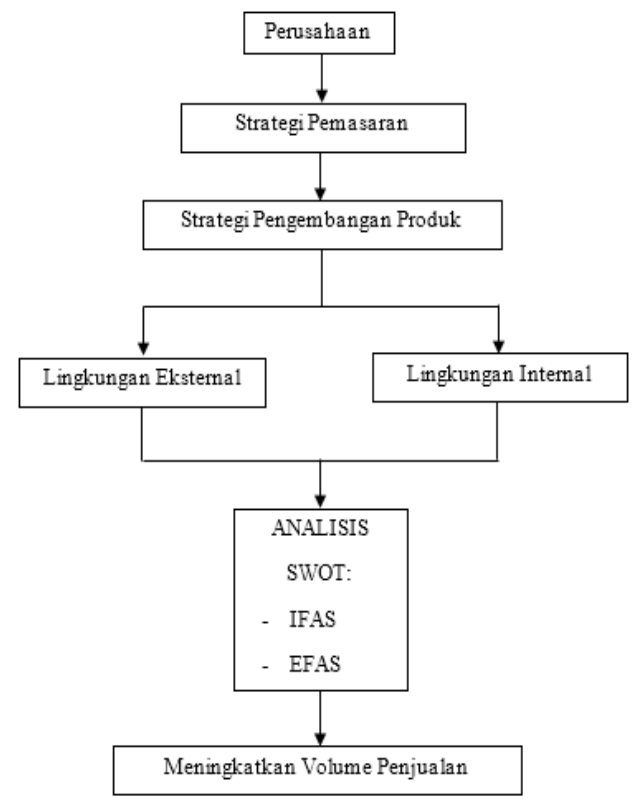

Gambar 2 Kerangka Berfiir

Pada kerangka berfikir diatas, penulis menggambarkan jalannya penelitian, yakni menganalisis lingkugan internal dan eksternal perusahaan terkait pengembangan produk yang dilakukan selama ini oleh perusahaan untuk mengetahui bagaimana dan seperti apa strategi pengembangan produk yang selama ini dilakukan, apakah 
telah sesuai dan mampu meningkatkan volume penjualan setiap tahunnya.

\section{Hipotesis}

Hipotesis dari penelitian ini adalah:

1) Diduga strategi pemasaran melalui pendekatan pengembangan produk berpengaruh terhadap peningkatan volume penjualan pada CV. Silvi MN Paradila.

2) Diduga strategi S-O (StrenghtOpportunities) yang sesuai untuk diterapkan pada CV. Silvi MN Paradila guna meningkatkan volume penjualan.

\section{METODE PENELITIAN}

\section{Waktu dan Lokasi}

Penelitian ini dilaksanakan pada mulai bulan November 2018 hingga April 2019 pada suatu usaha tenun yakni CV. Silvi MN Paradila yang berlokasi di Desa Parengan, Kecamatan Maduran, Kabupaten Lamongan.

\section{Metode Analisis Data}

Metode penelitian yang digunakan adalah deskriptif kualitatif. Sedangkan analisis yang digunakan dalam penelitian ini adalah analisis SWOT yang meliputi matriks IFAS (Internal Strategic Factor Analisis Summay), matriks EFAS (Eksternal Strategic Factor Analisis Summay) dan matriks SWOT. Perbedaan penelitian ini dengan penelitian yang lainnya terletak pada fokus penelitian, yakni implementasi strategi pemasaran yang berfokus pada pengembangan produk guna meningkatkan volume penjualan pada perusahaan yang diteliti yakni CV. Silvi MN Paradila.

\section{HASIL DAN PEMBAHASAN}

\section{Data Pendapatan}

Tabel 1.Pendapatan CV. Silvi MN Paradila (Rp) selama 3 tahun

\begin{tabular}{|l|l|l|}
\hline No. & Tahun & Total Pendapatan \\
\hline 1 & 2016 & 944.400 .000 \\
\hline 2 & 2017 & 987.200 .000 \\
\hline 3 & 2018 & 1.012 .000 .000 \\
\hline
\end{tabular}

Sumber: CV. Silvi MN Paradila, data diolah

Tabel 2. Matriks IFAS (Internal Factors Analysis Summary)

\begin{tabular}{|l|l|l|l|}
\hline $\begin{array}{l}\text { Faktor } \\
\text { Internal }\end{array}$ & Bobot & Rating & $\begin{array}{l}\text { Bobot } \\
\mathrm{x} \\
\text { Rating }\end{array}$ \\
\hline \multicolumn{2}{|l|}{ Kekuatan } & & \\
\hline $\begin{array}{l}\text { Kualitas } \\
\text { produk } \\
\text { terjaga karena } \\
\text { menggunakan } \\
\text { bahan-bahan } \\
\text { yang } \\
\text { berkualitas }\end{array}$ & 0,20 & 4 & 0,80 \\
\hline $\begin{array}{l}\text { Secara } \\
\text { berkala } \\
\text { membuat } \\
\text { desain-desain } \\
\text { dan motif } \\
\text { tenun baru } \\
\text { agar } \\
\text { konsumen } \\
\text { tidak merasa } \\
\text { bosan }\end{array}$ & 0,20 & 4 & 0,80 \\
\hline $\begin{array}{l}\text { Membuat dan } \\
\text { desain dan } \\
\text { motif yang } \\
\text { tidak hanya }\end{array}$ & 0,13 & 3 & 0,39 \\
\hline
\end{tabular}




\begin{tabular}{|c|c|c|c|}
\hline $\begin{array}{l}\text { Faktor } \\
\text { Internal }\end{array}$ & Bobot & Rating & $\begin{array}{l}\text { Bobot } \\
\mathrm{x} \\
\text { Rating }\end{array}$ \\
\hline $\begin{array}{l}\text { diminati } \\
\text { orang tua, } \\
\text { namun juga } \\
\text { cocok untuk } \\
\text { remaja } \\
\text { bahkan anak- } \\
\text { anak }\end{array}$ & & & \\
\hline $\begin{array}{l}\text { Tidak hanya } \\
\text { memasarkan } \\
\text { produk } \\
\text { berupa kain } \\
\text { tenun, CV. } \\
\text { SILVI MN } \\
\text { PARADILA } \\
\text { juga } \\
\text { memasarkan } \\
\text { produk dalam } \\
\text { bentuk } \\
\text { pakaian jadi }\end{array}$ & 0,11 & 2 & 0,22 \\
\hline SUB TOTAL & 0,64 & & 2,21 \\
\hline \multicolumn{4}{|l|}{ Kelemahan } \\
\hline $\begin{array}{l}\text { Masih } \\
\text { menggunakan } \\
\text { Alat Tenun } \\
\text { Bukan Mesin } \\
\text { (ATBM) } \\
\text { dalam proses } \\
\text { produsinya } \\
\text { sehingga } \\
\text { proses } \\
\text { produksi } \\
\text { membutuhkan } \\
\text { waktu yang } \\
\text { cukup lama. }\end{array}$ & 0,08 & 3 & 0,24 \\
\hline $\begin{array}{l}\text { Kurang } \\
\text { intensif dalam } \\
\text { penggunaan } \\
\text { media sosial } \\
\text { sebagai media } \\
\text { iklan }\end{array}$ & 0,16 & 2 & 0,32 \\
\hline $\begin{array}{l}\text { Rendahnya } \\
\text { kualitas } \\
\text { Sumber Daya } \\
\text { Manusia }\end{array}$ & 0,05 & 4 & 0,20 \\
\hline
\end{tabular}

\begin{tabular}{|l|l|l|l|}
\hline $\begin{array}{l}\text { Faktor } \\
\text { Internal }\end{array}$ & Bobot & Rating & $\begin{array}{l}\text { Bobot } \\
\mathrm{x} \\
\text { Rating }\end{array}$ \\
\hline (SDM) & 0,07 & 4 & 0,28 \\
\hline $\begin{array}{l}\text { Pemanfaatan } \\
\text { teknologi } \\
\text { yang dimiliki } \\
\text { belum } \\
\text { optimal }\end{array}$ & 0,36 & & 1,04 \\
\hline SUB TOTAL & 1 & & 3,25 \\
\hline TOTAL & 1 & \\
\hline
\end{tabular}

Sumber: Data diolah

Pada matriks pembobotan atas factor strategi internal (IFAS) pada tabel diatas diperoleh skor total 3,25 yang dapat dikategorikan baik, hal ini menunjukkan strategi internal kekuatan dan kelemahan pengembangan produk yang dimiliki oleh CV. Silvi MN Paradila di mungkinkan sebagai landasan perusahaan untuk melakukan rencana pertumbuhan dan perkembangan usaha di masa depan.

Tabel 3. Matriks EFAS (External Factors Analysis Summary)

\begin{tabular}{|l|l|l|l|}
\hline $\begin{array}{l}\text { Faktor } \\
\text { Eksternal }\end{array}$ & Bobot & Rating & $\begin{array}{l}\text { Xobot } \\
\text { Rating }\end{array}$ \\
\hline Peluang & & & \\
\hline $\begin{array}{l}\text { Bisa dikatakan } \\
\text { CV. SILVI MN } \\
\text { PARADILA } \\
\text { merupakan } \\
\text { satu-satunya } \\
\text { produsen kain } \\
\text { tenun di }\end{array}$ & 0,19 & 3 & 0,57 \\
\hline
\end{tabular}




\begin{tabular}{|l|l|l|l|}
\hline $\begin{array}{l}\text { Faktor } \\
\text { Eksternal }\end{array}$ & Bobot & Rating & $\begin{array}{l}\text { Xobot } \\
\text { Rating }\end{array}$ \\
\hline $\begin{array}{l}\text { wilayah } \\
\text { Kabupaten } \\
\text { Lamongan. }\end{array}$ & & & \\
\hline $\begin{array}{l}\text { Pakaian } \\
\text { merupakan } \\
\text { kebutuhan } \\
\text { primer yang } \\
\text { selalu } \\
\text { dibutuhkan } \\
\text { serta dunia } \\
\text { fashion } \\
\text { semakin } \\
\text { berkembang } \\
\text { seiring } \\
\text { berjalannya } \\
\text { waktu. }\end{array}$ & 0,22 & 4 & 0,88 \\
\hline $\begin{array}{l}\text { Semakin } \\
\text { berkembangnya } \\
\text { teknologi. }\end{array}$ & 0,10 & 2 & 0,20 \\
\hline $\begin{array}{l}\text { Terdapat } \\
\text { berbagai media } \\
\text { sosial yang } \\
\text { dapat } \\
\text { digunakan } \\
\text { sebagai median. }\end{array}$ & 0,15 & 3 & 0,45 \\
\hline $\begin{array}{l}\text { SUB TOTAL } \\
\text { Ancaman }\end{array}$ & 0,66 & \\
\hline
\end{tabular}

\begin{tabular}{|c|c|c|c|}
\hline $\begin{array}{l}\text { Faktor } \\
\text { Eksternal }\end{array}$ & Bobot & Rating & $\begin{array}{l}\text { Bobot } \\
\mathrm{x} \\
\text { Rating }\end{array}$ \\
\hline $\begin{array}{l}\text { Mempunyai } \\
\text { banyak pesaing } \\
\text { di wilayah } \\
\text { Jawa Timur }\end{array}$ & 0,16 & 3 & 0,48 \\
\hline $\begin{array}{l}\text { Dalam } \\
\text { persaingan } \\
\text { nasional } \\
\text { produk tenun } \\
\text { CV. SILVI MN } \\
\text { PARADILA } \\
\text { kalah pamor } \\
\text { dengan produk } \\
\text { asal Jepara, } \\
\text { Sintang dan } \\
\text { Toraja. }\end{array}$ & 0,09 & 2 & 0,18 \\
\hline $\begin{array}{l}\text { Melemahnya } \\
\text { nilai tukar } \\
\text { Rupiah. }\end{array}$ & 0,05 & 4 & 0,20 \\
\hline $\begin{array}{l}\text { Produk atau } \\
\text { desain baru } \\
\text { tidak diminati } \\
\text { oleh konsumen }\end{array}$ & 0,04 & 4 & 0,16 \\
\hline SUB TOTAL & 0,34 & & 1,02 \\
\hline TOTAL & 1 & & 3.12 \\
\hline
\end{tabular}

Sumber: Data diolah

Dari tabel Matriks EFAS, dapat disimpulkan bahwa CV. Silvi MN Paradila telah berhasil memanfaatkan peluang yang ada untuk menutupi factor-faktor yang 
menjadi ancaman. Hal ini dapat dilihat melalui besarnya skor peluang yaitu 2,10 yang lebih besar dari skor ancaman sebesar 1,02 .

\section{Diagram SWOT}

Pada diagram dibawah, dapat dilihat titik perpotongan sumbu $\mathrm{x}, \mathrm{y}$ berada di kudran 1. Titik perpotongan sumbu $\mathrm{x}$ di peroleh dari pengurangan skor peluang dengan ancaman, yakni sebesar (1.08) yang bernilai positif. Sedangkan titik perpotongan sumbu $y$ diperoleh dari pengurangan skor kekuatan dengan kelemahan (1.17) yang bernilai positif.

Titik perpotongan sumbu $\mathrm{x}, \mathrm{y}$ yang berada dikuadran 1 menunjukan bahwa $\mathrm{CV}$. Silvi MN Paradila berada pada kondisi yang sangat baik. Dengan melakukan strategi agresif CV. Silvi MN Paradila akan mampu bersaing dan meningkatkan penjualannya.

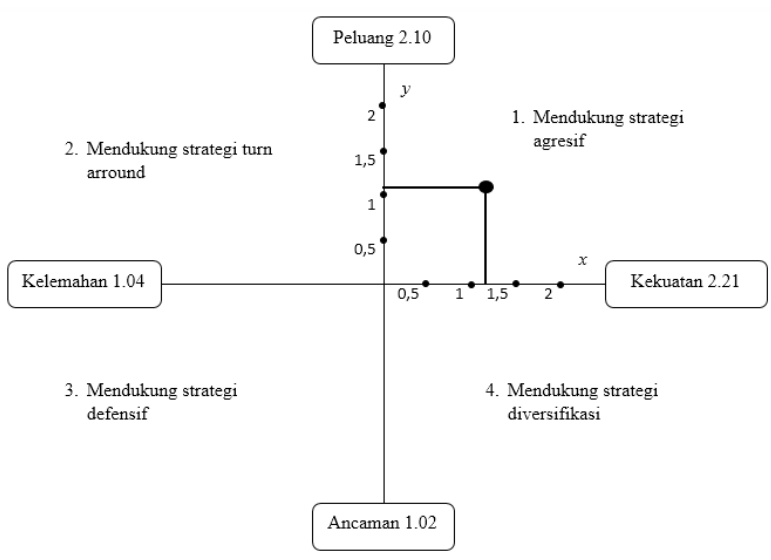

Gambar 2. Diagram SWOT

\section{KESIMPULAN}

Berdasarkan hasil pembahasan dan penelitian yang dilakukan sesuai dengan tujuan hipotesis, maka dapat ditarik kesimpulan sebagai berikut:

1) Dilihat dari data pendapatan pada tahun 2016 hingga 2018 yang selalu mengalami kenaikan pendapatan, maka strategi pengembangan produk yang selama ini dilakukan oleh CV. Silvi MN Paradila dapat dinyatakan berhasil. Dengan selalu menjaga kualitas produk serta memperbarui motif produk kain tenun setiap bulan, CV. Silvi MN Paradila berhasil mempertahankan konsumennya dan meningkatkan penjualannya dan berimbas pada peningkatan pendapatan dalam setiap tahunnya.

2) Dari hasil analisis faktor internal (IFAS) dan faktor eksternal (EFAS), diperoleh nilai skor sebagai berikut: kekuatan (strenght) sebesar 2.21, kelemahan (weakness) sebesar 1.04, peluang (opportunity) sebesar 2.10 dan ancaman (threat) sebesar 1.02. Skor kekuatan menang dari skor kelemahan, yakni selisih 1.17 (+). Dan Skor peluang menang dari skor ancaman, yakni selisih 1.08 (+). Berdasarkan skor tersebut, dapat dikatakan bahwa kondisi CV. Silvi MN Paradila berada pada kuadran I, yakni mendukung 
strategi agresif. Hal ini menunjukkan bahwa CV. Silvi MN Paradila berada pada kondisi yang baik serta dengan memanfaatkan kekuatan dan peluang yang dimiliki serta meminimalisir kelemahan serta ancaman maka CV. Silvi MN Paradila akan semakin baik kedepannya.

\section{DAFTAR PUSTAKA}

Daryono. 2011. Manajemen Pemasaran. CV Yrama Widya, Bandung.

Kotler, Philip dan Gary Amstrong. 2014. Principles of Marketing. Jilid 1 Terjemahan Bob Sabran. Erlangga, Jakarta.

Lupiyoadi, Rambat. 2013. Manajemen Pemasaran Jasa Berbasis Kompetensi. Salemba Empat, Jakarta.

Nuary, Nizar Sapta. 2016. Strategi Pemasaran dengan Pendekatan Analisis SWOT pada PT. Super Sukses Motor Banjarmasin. Jurnal Ilmilah Ekonomi Bisnis, Vo 2, No 1.

Oentoro, Deliyanti. 2012. Manajemen Pemasaran Modern. LaksBang PRESSindo, Yogyakarta

Rangkuti, Freddy. 2016. Teknik Membedah Kasus Bisnis Analisis SWOT. Gramedia, Jakarta. 
